\title{
miR-494.3p expression in synovial sarcoma: Role of CXCR4 as a potential target gene
}

\author{
LAURA PAZZAGLIA $^{1}$, SERENA POLLINO ${ }^{1}$, MATTIA VITALE $^{1}$, ELISA BIENTINESI ${ }^{1}$, \\ STEFANIA BENINI ${ }^{2}$, CRISTINA FERRARI ${ }^{1}$, EMANUELA PALMERINI ${ }^{3}$, \\ MARCO GAMBAROTTI ${ }^{2}$, PIERO PICCI ${ }^{1}$ and MARIA SERENA BENASSI ${ }^{1}$ \\ ${ }^{1}$ Laboratory of Experimental Oncology, ${ }^{2}$ Department of Pathology and ${ }^{3}$ Chemotherapy Unit, \\ IRCCS, Rizzoli Orthopedic Institute, I-40136 Bologna, Italy
}

Received May 29, 2018; Accepted October 4, 2018

DOI: $10.3892 /$ ijo.2018.4627

\begin{abstract}
Synovial sarcoma (SS) is a rare tumour, with dismal survival when metastasis occurs. SS contains a characteristic translocation $(\mathrm{X} ; 18)(\mathrm{p} 11 ; \mathrm{q} 11)$ and the fusion genes appear to be mutually exclusive and concordant in primary and metastatic tumours. Novel prognostic and predictive factors are required. The C-X-C motif chemokine ligand 12 (CXCL12)/C-X-C chemokine receptor 4 (CXCR4) axis is involved in tumour development and metastatic spread in many types of cancer and previous data have demonstrated a pivotal role of CXCR4 in SS cell migration and invasion. Bioinformatics and biological data indicated CXCR4 is a possible candidate target of miR-494.3p, known to be involved in tumour progression. In this study, we analysed the expression of miR-494.3p and its potential target, CXCR4, in a series of SS specimens. A significantly lower miR-494.3p expression was found in the tumour compared to normal tissue associated with higher levels of CXCR4 both at the gene and protein level. The role of CXCR4 as a potential target of miR-494.3p was assessed in two SS cell lines (SW982 and SYO-I). Transfection with miR-494.3p expression plasmid led to a marked decrease in CXCR4 gene and protein expression, concomitant with a transitory decrease in cell proliferation and migration. The SYO-I cells also responded with an increased apoptotic fraction. The data of this study also demonstrate that the downregulation of miR-494.3p in SS surgical specimens, concomitant with an increased expression of its potential target, CXCR4, was more evident in the metastatic subset. In vitro experiments confirmed that miR-494.3p functioned as a tumour suppressor through the involvement of CXCR4 and ongoing studies are directed to better clarify its role in SS therapeutic strategies.
\end{abstract}

Correspondence to: Dr Laura Pazzaglia, Laboratory of Experimental Oncology, IRCCS, Rizzoli Orthopedic Institute, Via di Barbiano 1/10, I-40136 Bologna, Italy

E-mail: laura.pazzaglia@ior.it

Key words: synovial sarcoma, microRNA-494.3p, C-X-C chemokine receptor 4 , biomarker, cell migration

\section{Introduction}

Synovial sarcoma (SS) is a rare tumour, with a dismal survival when metastasis occurs. SS contains a characteristic translocation $(\mathrm{X} ; 18)(\mathrm{p} 11 ; \mathrm{q} 11)$, representing the fusion of SYT on chromosome 18 with either $S S X 1$ or $S S X 2$, or rarely $S S X 4$ on chromosome X. The resulting fusion genes appear to be mutually exclusive and concordant in primary and metastatic tumours. The 5-year survival rate is $55 \%$ for axial SS and $84 \%$ for SS of the extremities. Currently, biological factors are still unreliable for predicting the aggressiveness and clinical evolution of the tumour (1).

A tumour can influence its microenvironment by releasing extracellular signals, promoting tumour angiogenesis and inducing the inflammatory response, while immune cells in the microenvironment can affect the growth and evolution of cancer cells. The association between cancer cells and their microenvironment contributes to tumour heterogeneity (2) and is crucial for cancer progression. $\mathrm{C}-\mathrm{X}$-C chemokine receptor 4 (CXCR4) is a seven-transmembrane G protein-coupled chemokine receptor commonly expressed in tumour cells and is involved in cell migration and invasion, as well as in angiogenesis (3). The deregulated expression of CXCR4 has been detected in several human cancers, including melanoma, colon cancer (4), breast (5) and pancreatic cancer (6). CXCR4, by binding its ligand CXCL12 (SDF-1), activates cell signalling pathways promoting proliferation, migration and the development of metastasis $(7,8)$, also playing a role in normal stem cell homing (3). Previous studies have demonstrated that high expression levels of CXCR4 activated by CXCL12 are associated with a poor prognosis and a high rate of metastasis in bone and soft tissue sarcomas (STS) $(9,10)$, also showing the pivotal role of CXCR4 in cancer cell migration between the primary and metastatic site in SS. By multivariate analysis, we recently reported that the nuclear protein expression of CXCR4 was an independent adverse prognostic factor linked to the use of chemotherapy for the survival of patients with SS, suggesting a role of CXCR4 in drug resistance (11). MicroRNAs (miRNAs or miRs) are involved in post-transcriptional gene expression regulation and control important physiological processes, such as development, cell differentiation and cell signalling $(12,13)$. The altered expression of miRNAs is strongly associated with the malignant phenotype and there are data reporting a strong 
association between miRNA expression, patient age and STS prognosis $(14,15)$. miR-494.3p is involved in tumour progression and has been previously described as a CXCR4 regulator in prostate (16) and breast cancer cells, where its levels were significantly lower than those in normal breast epithelial cells (17). In chondrosarcoma, miR-494 has been shown to significantly inhibit cell proliferation, migration and invasion in vitro and in vivo (18), whereas another study demonstrated that it was downregulated in osteosarcoma when compared to normal tissue. In osteosarcoma cell lines, miR-494 restoration has been shown to inhibit cell proliferation, colony formation, migration and invasion (19). In this study, we analysed the expression of CXCR4 and miR-494.3p, in a series of SS specimens and verified that the modulation of CXCR4 mediated by the ectopic expression of miR-494.3p suppressed SS cell proliferation and migration.

\section{Materials and methods}

Tumour specimens. Forty-two primary monophasic SS specimens were selected from the Rizzoli Orthopedic Institute Biobank. All the demographic and clinicopathological data of the patients were collected (Table I). The specimens were from 22 males and 20 females with a mean age of 43 years; 29 patients developed metastases and 24 succumbed to the disease. The average follow-up time was 90 months (range, 13-70 months). All the samples were treated in accordance with the authorizations issued by the Ethics Committee of the Rizzoli Orthopedic Institute (no. 0033276) and written informed consent was obtained from all patients. Fresh and paraffin-embedded non-necrotic tissue $(\geq 90 \%$ viable tumour cells) was used. Following the revision of the histological slides according to histopathological and immunohistochemical criteria and the presence of SS18 (SYT) gene rearrangement and fusion transcripts (SSX1 and SSX2) the diagnosis was confirmed by pathologists. A total of 20 non-paired normal tissues were used as controls.

Synovial sarcoma cell lines. The human synovial sarcoma SW982 cell line (no. HTB-93) was obtained from the American Type Culture Collection (ATCC, Manassas, VA, USA) and the SYO-I cell line was kindly provided by Dr Kawai (Department of Orthopaedic Surgery, National Cancer Center Hospital, Tokyo, Japan). The cell lines were routinely cultured using $\alpha$-MEM medium supplemented with $10 \% \mathrm{FBS}$, L-glutamine $(2 \mathrm{mM}), 100 \mathrm{U} / \mathrm{ml}$ penicillin and $100 \mu \mathrm{g} / \mathrm{ml}$ streptomycin (Invitrogen/Thermo Fisher Scientific, Waltham, MA, USA) at $37^{\circ} \mathrm{C}$ in a $5 \% \mathrm{CO}_{2}$ humidified incubator.

RNA extraction. Total RNA was extracted using TRizol reagent (Invitrogen/Thermo Fisher Scientific) from the 42 SS tissue samples, 20 non-tumour tissues and the two SS cell lines (SW982 and SYO-I) following the manufacturer's instructions.

miRNA expression in clinical specimens. Reverse transcription and quantitative PCR (qPCR) of miR-494.3p (TaqMan miRNA assay no. 002365; Applied Biosystems/Thermo Fisher Scientific) was performed in the 42 SS and 20 non-paired normal tissues following the TaqMan MicroRNA assay protocol. miRNA expression was quantified by the $\Delta \Delta \mathrm{Cq}$ comparative method using a pool of normal lymphocytes as a calibrator (20). Data were normalized to the endogenous reference RNU44 (TaqMan miRNA assay no. 001094), following Applied Biosystems indications (TaqMan miRNA assay no. 4373384; Applied Biosystems/Thermo Fisher Scientific).

CXCR4 gene expression in clinical specimens. CXCR4 expression was quantified in $42 \mathrm{SS}$ and in 20 non-tumour tissues by TaqMan Expression Assay (Hs00607978_sl; Applied Biosystems/Thermo Fisher Scientific) according to manufacturer's instructions following reverse transcription using the SuperScript ${ }^{\mathrm{TM}}$ VILO $^{\mathrm{TM}}$ cDNA Synthesis kit (Applied Biosystems/Thermo Fisher Scientific). The expression of target genes was calculated by the $\Delta \Delta \mathrm{Cq}$ comparative method and normalized to the ACTB housekeeping gene (Hs99999903_m1 gene; TaqMan Expression Assays; Applied Biosystems/Thermo Fisher Scientific). A pool of normal lymphocytes was used as a calibrator.

Western blot analysis of CXCR4 protein expression in clinical specimens. According to standard procedures, protein extracts from the SS tissues and non-tumour tissues were prepared by mincing and homogenizing fresh samples in extraction buffer $(50 \mathrm{mM}$ Tris- $\mathrm{HCl}$ at $\mathrm{pH} 8.0,150 \mathrm{mM} \mathrm{NaCl}, 1 \mathrm{mM}$ DTT, $50 \mathrm{mM}$ NaF, $0.5 \%$ sodium deoxycholate, $0.1 \%$ SDS, $1 \%$ NP-40 and $0.1 \mathrm{mM}$ PMFS) with complete mixture of protease inhibitors (Roche Diagnostics, Laval, QC, Canada). Protein extracts were obtained by lysis in 100-400 $\mu 1$ lysis buffer [20 mM Tris- $\mathrm{HCl}$ ( $\mathrm{pH}$ 7.5), $150 \mathrm{mM} \mathrm{NaCl}, 2.5 \mathrm{mM}$ sodium pyrophosphate, $1 \mathrm{mM}$ glycerol phosphate, $1 \mathrm{mM} \mathrm{Na}_{3} \mathrm{VO}_{4}, 1 \mathrm{mM}$ EDTA and $1 \%$ Triton] with complete protease inhibitor mixture. A total of $50 \mu \mathrm{g}$ of protein extracts were prepared and analysed by $12 \%$ SDS-PAGE. Following nitrocellulose blot transfer and blocking using $5 \%$ milk in TBST $1 \mathrm{X}$ at room temperature for $1 \mathrm{~h}$, the membranes were incubated with a commercially available monoclonal antibody, anti-CXCR4 (ab2074, Abcam, Cambridge, UK) diluted 1:1,000, overnight in $4^{\circ} \mathrm{C}$ on a shaker. Anti-rabbit antibody conjugated to horseradish peroxidase (cat. no. NA934V; GE Healthcare, Chicago, IL, USA) was used as a secondary antibody at room temperature for $1 \mathrm{~h}$. Proteins were visualized by incubation with ECL (EuroClone, Milan, Italy) and quantified by densitometric analysis using a GS-800 imaging densitometer and Quantity One Software (Bio-Rad, Hercules, CA, USA). A rabbit anti-actin antibody (cat. no. SAB5500001; Sigma Chemical Co, St. Louis, MO, USA) diluited 1:50,000 was used as a loading control.

miR-494.3p transfection in SS cell lines. The SW982 and SYO-I cell lines were seeded at a density of $2.5 \times 10^{5}$ cells/well in 6-well plates in $2 \mathrm{ml}$ of complete medium containing $10 \%$ FCS for $24 \mathrm{~h}$. Transfection was performed using Lipofectamine 2000 (Invitrogen/Thermo Fisher Scientific) with $50 \mathrm{nM}$ miR-494.3p precursor (cod. PM12409; Ambion Inc., Austin, TX, USA) and miRNA negative precursor was used as a negative control (scramble) (cod. AM17110; Ambion). The transfection efficiency was monitored at 48 and $72 \mathrm{~h}$ post-transfection by flow cytometry (FACSCalibur; BD Biosciences, San Jose, CA, USA) using $\mathrm{Cy}^{\mathrm{TM}} 3$ and $\mathrm{FAM}^{\mathrm{TM}}$ dye-labelled Pre-miR Negative Controls (cod. AM17120; Ambion) and RT-PCR according to the TaqMan MicroRNA assay protocol for the CXCR4 target gene. The results were quantified by the $\Delta \Delta \mathrm{Cq}$ method using 
Table I. Clinicopathological features of patients with SS.

\begin{tabular}{|c|c|c|c|c|c|c|}
\hline Case & Sex & Age & Site & Metastasis & Follow-up (months) & Outcome \\
\hline 1 & $\mathrm{~F}$ & 17 & Elbow & $\mathrm{x}$ & 55 & DOD \\
\hline 2 & $\mathrm{~F}$ & 32 & Thigh & $\mathrm{x}$ & 24 & DOD \\
\hline 3 & $\mathrm{~F}$ & 51 & Thigh & $\mathrm{x}$ & 110 & DOD \\
\hline 4 & M & 48 & Thigh & $\mathrm{x}$ & 16 & DOD \\
\hline 5 & M & 63 & Paraspinal & $\mathrm{x}$ & 83 & DOD \\
\hline 6 & $\mathrm{~F}$ & 40 & Popliteus & $\mathrm{x}$ & 43 & DOD \\
\hline 7 & $\mathrm{~F}$ & 63 & Foot & $\mathrm{x}$ & 20 & DOD \\
\hline 8 & M & 40 & Leg & $\mathrm{x}$ & 9 & DOD \\
\hline 9 & $\mathrm{~F}$ & 41 & Popliteus & $\mathrm{x}$ & 43 & DOD \\
\hline 10 & M & 47 & Thigh & $\mathrm{x}$ & 49 & DOD \\
\hline 11 & $\mathrm{~F}$ & 51 & Thigh & $\mathrm{x}$ & 203 & DOD \\
\hline 12 & $\mathrm{~F}$ & 32 & Thigh & $\mathrm{x}$ & 24 & DOD \\
\hline 13 & M & 49 & Forearm & $\mathrm{x}$ & 63 & NED \\
\hline 14 & M & 29 & Popliteus & $\mathrm{x}$ & 120 & NED \\
\hline 15 & M & 64 & Thigh & $\mathrm{x}$ & 50 & DOD \\
\hline 16 & M & 70 & Scapular girdle & $\mathrm{x}$ & 8 & DOD \\
\hline 17 & M & 37 & Knee & $\mathrm{x}$ & 66 & DOD \\
\hline 18 & $\mathrm{~F}$ & 59 & Foot & & 72 & NED \\
\hline 19 & M & 26 & Gluteus & $\mathrm{x}$ & 58 & DOD \\
\hline 20 & $\mathrm{~F}$ & 57 & Foot & $\mathrm{x}$ & 67 & DOD \\
\hline 21 & M & 31 & Thigh & $\mathrm{x}$ & 12 & DOD \\
\hline 22 & M & 14 & Foot & $\mathrm{x}$ & 93 & NED \\
\hline 23 & $\mathrm{~F}$ & 69 & Elbow & & 143 & NED \\
\hline 24 & $\mathrm{~F}$ & 16 & Gluteus & & 131 & NED \\
\hline 25 & M & 61 & Wrist & & 153 & NED \\
\hline 26 & $\mathrm{M}$ & 46 & Forearm & & 150 & NED \\
\hline 27 & $\mathrm{M}$ & 39 & Leg & $\mathrm{x}$ & 23 & NED \\
\hline 28 & $\mathrm{~F}$ & 63 & Foot & $\mathrm{X}$ & 20 & DOD \\
\hline 29 & $\mathrm{M}$ & 57 & Foot & $\mathrm{x}$ & 22 & DOD \\
\hline 30 & $\mathrm{~F}$ & 51 & Thigh & $\mathrm{X}$ & 54 & DOD \\
\hline 31 & M & 36 & Leg & & 176 & NED \\
\hline 32 & $\mathrm{M}$ & 57 & Popliteus & & 137 & NED \\
\hline 33 & $\mathrm{~F}$ & 13 & Gluteus & & 183 & NED \\
\hline 34 & $\mathrm{~F}$ & 46 & Leg & $\mathrm{x}$ & 88 & DOD \\
\hline 35 & $\mathrm{M}$ & 29 & Leg & & 170 & NED \\
\hline 36 & $\mathrm{M}$ & 38 & Thigh & & 138 & NED \\
\hline 37 & $\mathrm{M}$ & 43 & Thigh & $\mathrm{x}$ & 310 & NED \\
\hline 38 & $\mathrm{~F}$ & 58 & Thigh & & 160 & NED \\
\hline 139 & $\mathrm{~F}$ & 58 & Foot & $\mathrm{x}$ & 44 & DOD \\
\hline 40 & $\mathrm{~F}$ & 21 & Elbow & & 116 & NED \\
\hline 41 & M & 27 & Arm & & 260 & NED \\
\hline 42 & $\mathrm{~F}$ & 33 & Foot & $\mathrm{x}$ & 20 & DOD \\
\hline
\end{tabular}

SS, synovial sarcoma; F, female; M, male; NED, no evidence of disease; DOD, died of disease.

TaqMan Expression Assays (Hs00607978_s1) and normalized to the ACTB housekeeping gene (Hs99999903_m1) (Applied Biosystems/Thermo Fisher Scientific).

Flow cytometric analysis of CXCR4 in SS cell lines. The SW982 and SYO-I cells were stained with anti-CXCR4 antibody for
30 min at room temperature (ab2074; Abcam; 1:100 dilution in phosphate-buffered saline (PBS)]. Following washes with wash buffer, the cells were incubated at room temperature with a goat-anti-rabbit FITC-conjugated secondary antibody (cat. no. 31635; Thermo Fisher Scientific) (1:80 dilution in PBS) for $1 \mathrm{~h}$ in the dark. Following two additional washes in wash 

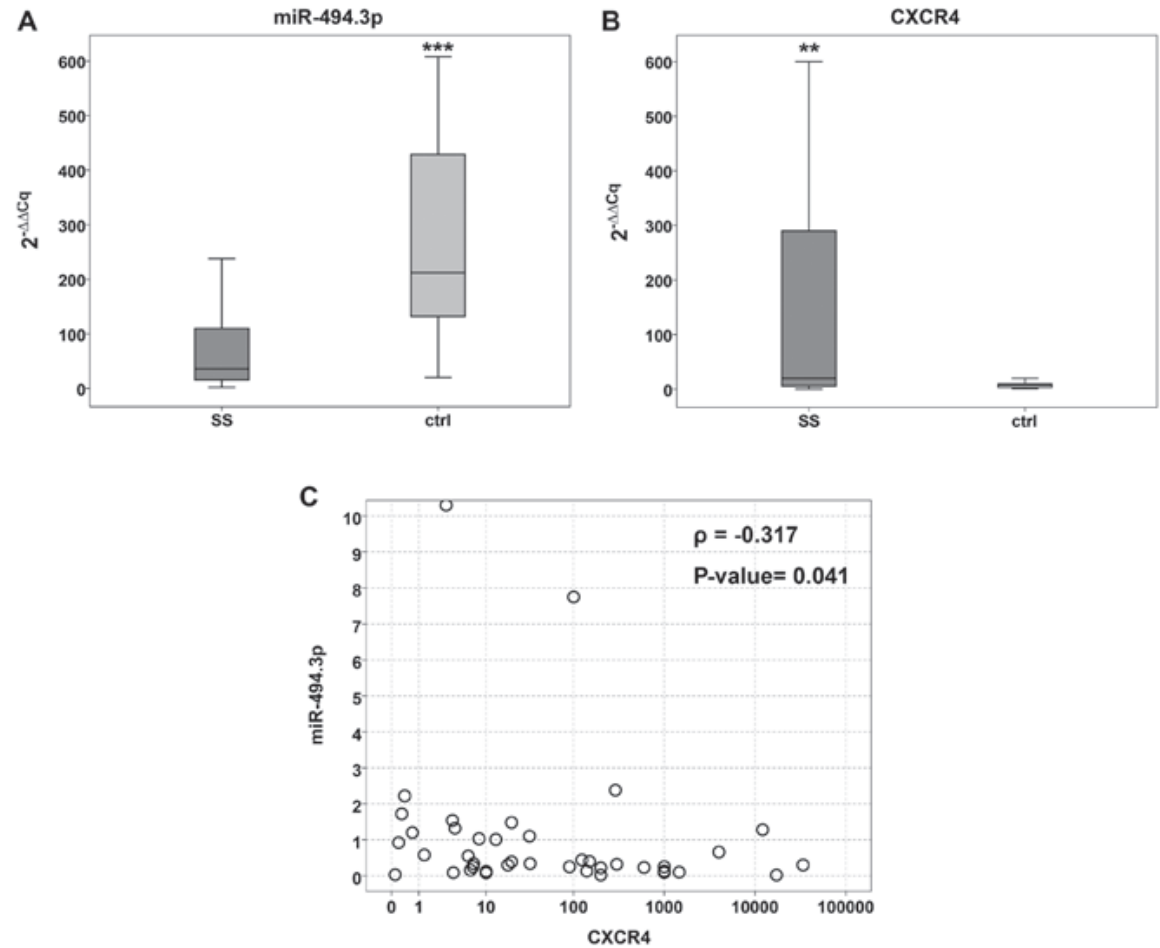

Figure 1. Relative levels of (A) miR-494.3p and (B) CXCR4 mRNA expression in primary SS and normal tissue. Mann-Whitney analysis revealed statistically significant differences; ${ }^{* *} \mathrm{P} \leq 0.01$ and ${ }^{* * *} \mathrm{P} \leq 0.001$. (C) Spearman's correlation analysis between miR-494.3p and mRNA CXCR4 expression in SS. SS, synovial sarcoma.

buffer, flow cytometry was performed using a FACSCalibur flow cytometer (BD Biosciences).

Cell growth assay. The number of adherent, viable cells was assessed microscopically using an improved Neubauer cell counting chamber (Incofar, Modena, Italy) in non-transfected and transfected cells at 48 and $72 \mathrm{~h}$ from transfection. The viable cells were then quantified by a Trypan blue exclusion assay. The cells were washed once in PBS, harvested by trypsinization and stained with 1X trypan blue solution (cat. no. 15250-061; Thermo Fisher Scientific). Cell viability was assessed as the percentage of cells that excluded trypan blue.

Apoptosis assay. Apoptotic cell death was analysed in non-transfected and transfected cells at 48 and $72 \mathrm{~h}$ from transfection with the Annexin V-FITC apoptosis detection kit (MEBCYTO Apoptosis kit, MBL International, Woburn, MA, USA). Following the manufacturer's instructions, adherent cells were trypsinized, suspended in $500 \mu \mathrm{l}$ of staining solution containing FITC-conjugated Annexin V antibody and propidium iodide (PI) and after $30 \mathrm{~min}$ of incubation on ice were analysed by flow cytometry using a FACSCalibur flow cytometer and CellQuest Software (BD Biosciences).

Scratch wound-healing assay. Cell migration ability was determined using a scratch wound-healing assay. The SW982 and SYO-I adherent cells were rinsed with PBS to remove floating cells, and a vertical line was scratched with a sterile $200 \mu \mathrm{l}$ pipette (time 0 ) at $48 \mathrm{~h}$ post-transfection. The wound closure was then monitored at $6,18,24,36$ and 72 . The areas were measured using IMAGEJ v.1.45r software (http://rsbweb. nih.gov/ij/).
Statistical analysis. miRNA expression is presented as the $2^{-\Delta \Delta C q}$ value for each sample. Values of the median $(\mathrm{m})$ and the 25th-75th percentile were calculated within the two subsets. A non-parametric Mann-Whitney U test was performed to compare miRNA median levels in the subsets and Spearman's rank coefficient was used for correlation analysis. The non-parametric Wilcoxon text was performed for protein analysis. In vitro experiments were performed 3 times and statistical significance was analysed by a Student's t-test. For all analyses, a value of $\mathrm{P}<0.05$ was considered to indicate a statistically significant difference.

\section{Results}

miRNA and CXCR4 expression in specimens. miR-494.3p expression analysis performed in the 42 SS samples and 20 non-tumour tissues. The tumour tissues exhibited significantly lower median values $\left(2^{-\Delta \Delta \mathrm{Cq}}\right)$ in the tumours compared to the controls (36.5; 25 th-75th $=15.2-112$ and $212 ; 25$ th-75th $=127-475$, respectively) $(\mathrm{P}=0.001)$ (Fig. 1A).

Conversely, CXCR4 mRNA expression was significantly higher in the tumour (median value 20; 25 th- 75th=5.5-292) compared to the non-tumour tissue (median value $=7.5$; 25th-75th=3-10) $(\mathrm{P}=0.01)($ Fig. 1B). Spearman's correlation analysis performed on the 42 SS samples confirmed the significant negative correlation between CXCR4 and miR-494.3p expression ( $\mathrm{Q}=-0.317, \mathrm{P}=0.041)$ (Fig. 1C).

The high expression of the CXCR4 gene was concomitant with the presence of a marked $44 \mathrm{kDa}$ migration band detected by western blot analysis. Densitometric analysis revealed that CXCR4 protein levels were higher in the SS that in normal adjacent tissue $(30.92 ; 25$ th-75th $=18.75-53$ and 6.75 ; 


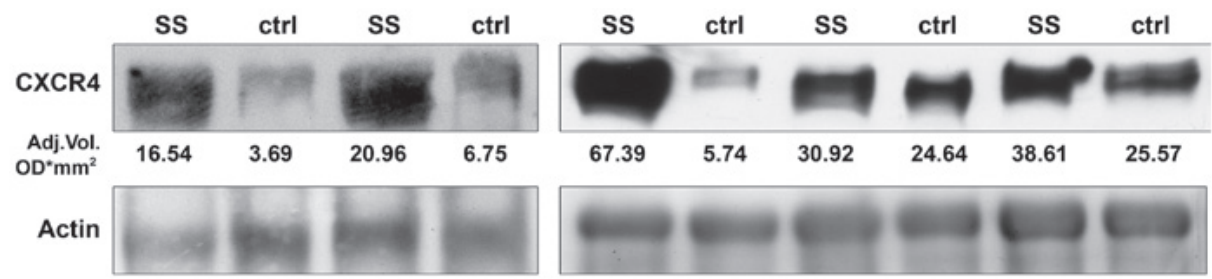

Figure 2. Representative detection of CXCR4 protein expression in SS primary and non-tumour tissue. A higher level of CXCR4 (44 kDa) was observed in SS when compared to normal tissue (ctrl). SS, synovial sarcoma; ctrl, control.

A

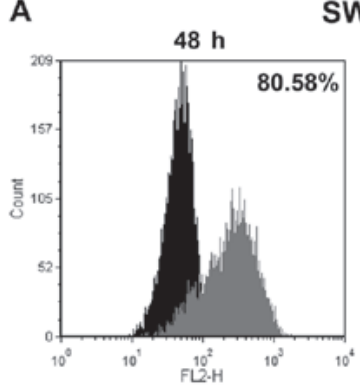

B

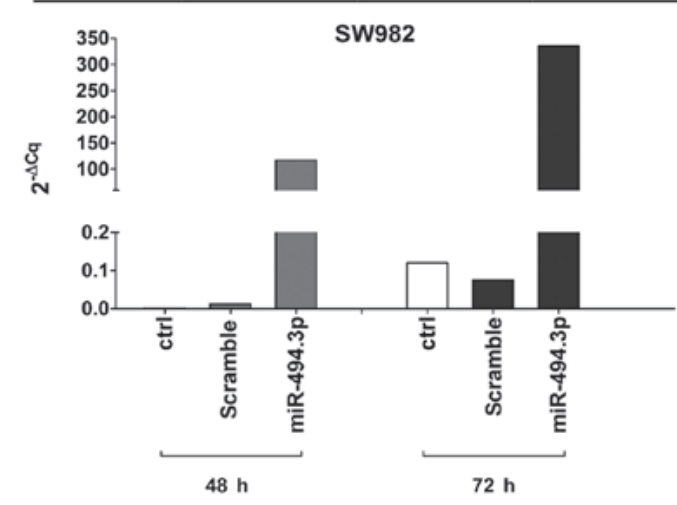

SW982

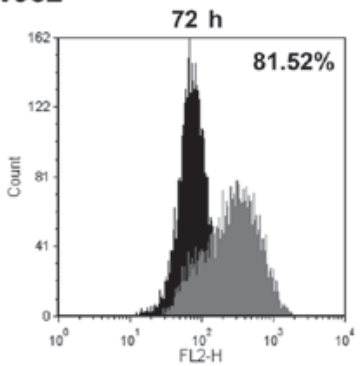

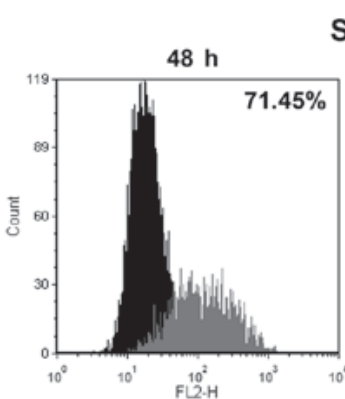

SYO-I

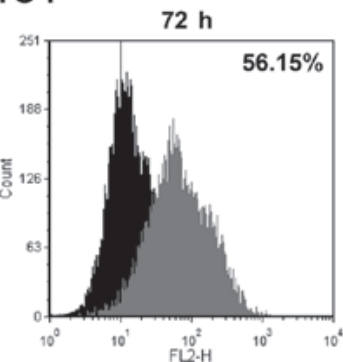

$\operatorname{miR}-494.3 p$

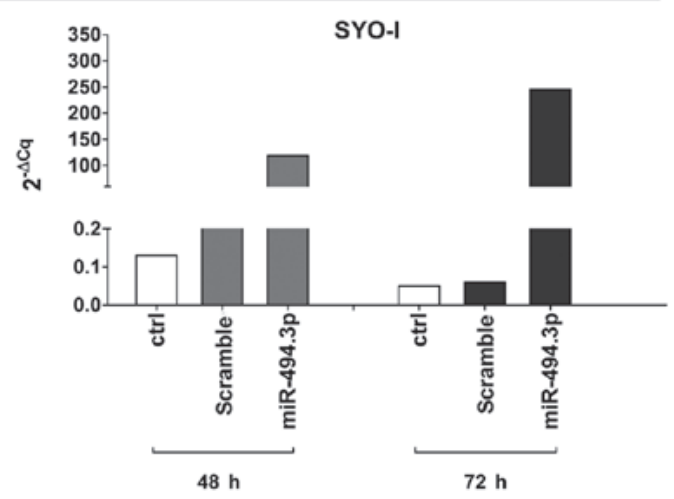

C

CXCR4
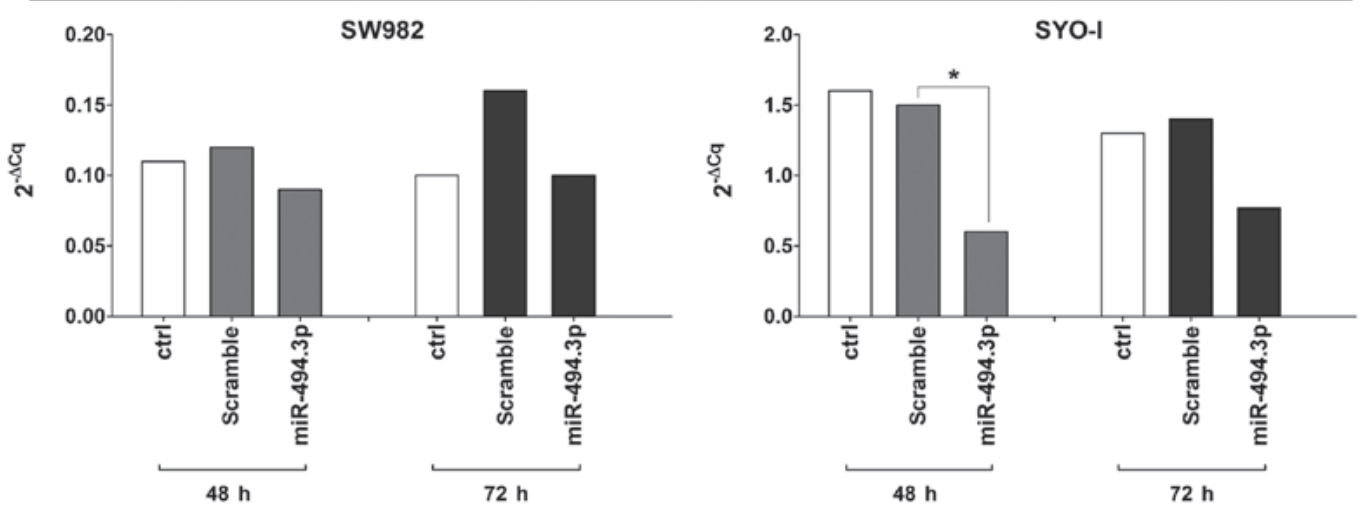

Figure 3. miR-494.3p transfection efficiency. (A) Efficiency was measured at 48 and $72 \mathrm{~h}$ following transfection by flow cytometry. Black graphic indicates control miRNA precursor (scramble) an d grey graphic indicates miR-494.3p precursor molecules. (B) Efficiency of transfection with pre-miR miR-494.3p precursor in SW982 and SYO-I cell lines by RT-qPCR (2- ${ }^{-\Delta C q}$ values). (C) CXCR4 expression in pre-miR miR-494.3p precursor transfected SS cells by RT-qPCR ( $2^{-\Delta \Delta C q}$ values). Statistically significant differences were determined between miRNA-transfected cells and the scramble control using the t-test. ${ }^{*} \mathrm{P} \leq 0.05$; ctrl, control, cells under basal condition.

25 th-75th $=4.71-25.10$ respectively) with a difference at the limit of statistical significance ( $\mathrm{P}=0.063)$ (Fig. 2).

When the tumour population was divided according to clinical follow-up, we found lower miR-494.3p median levels in the metastatic compared to the non-metastatic subset (34.0; 25th-75th=13-115 and 56.0; 25th-75th=30-103, respectively) $(\mathrm{P}=0.4)$, while the CXCR4 mRNA levels were higher in the first group (100; 6.2-1000 and 18.1; 0.8-32.5, respectively), revealing a difference at the limit of statistical significance $(\mathrm{P}=0.06)$. No significant differences were related to patient outcome (Table II). 

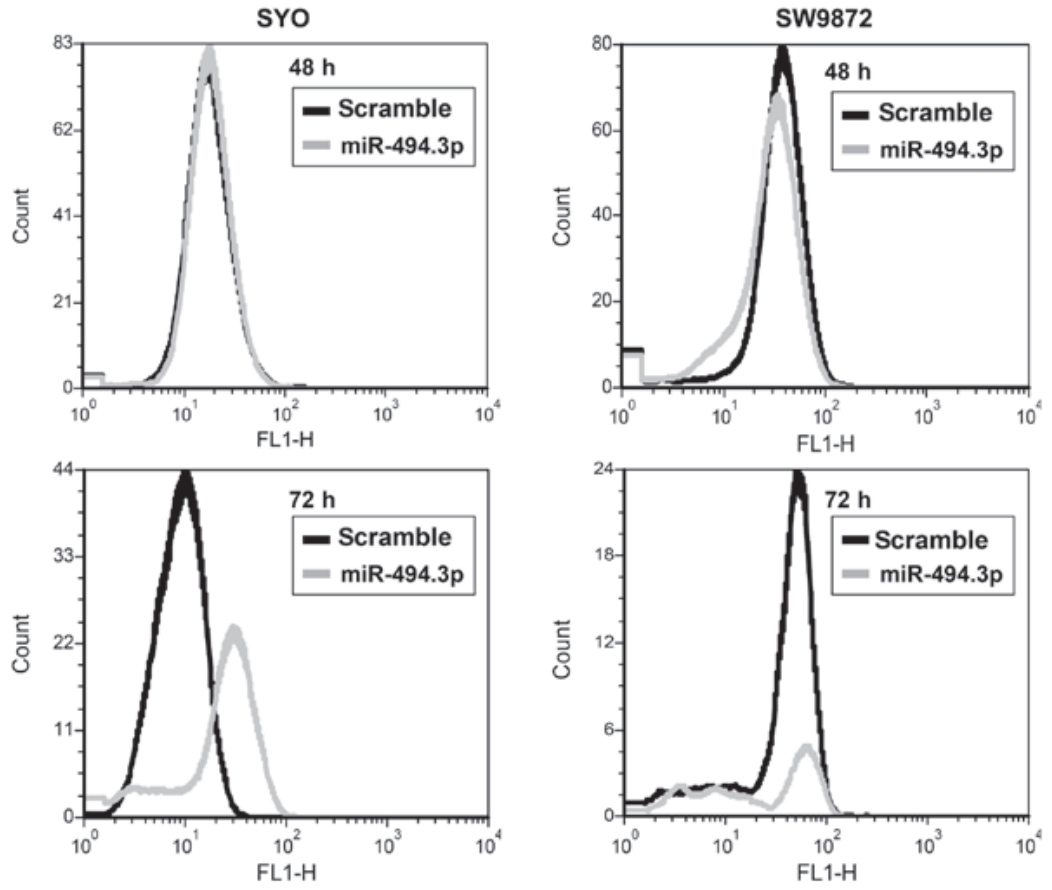

Figure 4. CXCR4 protein expression in SYO-I and SW982 following transfection with miR-494.3p precursor at 48 and $72 \mathrm{~h}$. FACS analysis revealed a deceased expression of CXCR4 for both cell lines.

A

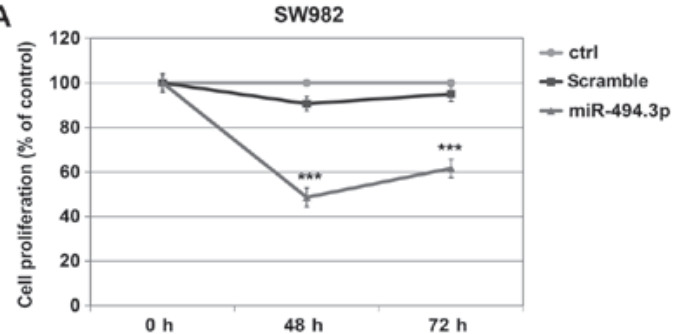

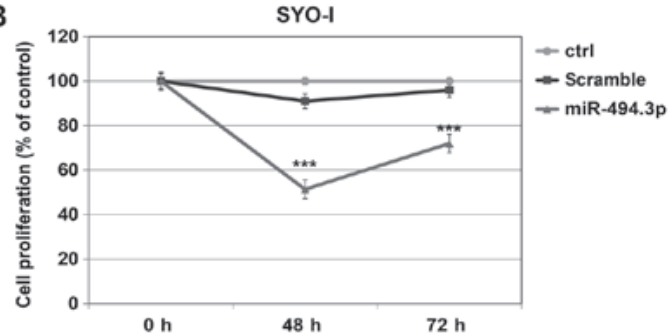

Figure 5. Ectopic miR-494.3p expression and cell proliferation. miRNA transfection led to a significant decrease in the proliferation of (A) SW982 and (B) SYO-I cells. Statistically significant differences were determined between miRNA-transfected cells and the scramble control using the t-test. ${ }^{* * *} \mathrm{P} \leq 0.001$; ctrl, control, cells under basal condition.

Table II. miR-494.3p and CXCR4 median expression level.

\section{$25 \mathrm{P}$ Median $2^{-\Delta \Delta \mathrm{CT}} \quad 75 \mathrm{P} \quad \mathrm{P}$-value}

\begin{tabular}{lllll}
\hline miR-494.3p & & & & \\
$\quad$ Non-metastatic & 30 & 56 & 103 & 0.4 \\
Metastatic & 13 & 34 & 115 & \\
miR-494.3p & & & & \\
$\quad \begin{array}{l}\text { Alive patients } \\
\text { Deceased patients }\end{array}$ & 28.7 & 51 & 114.2 & $>0.05$ \\
CXCR4 & & 32 & 112.5 & \\
$\quad$ Non-metastatic & 0.8 & 18.1 & 32.5 & 0.06 \\
Metastatic & 6.2 & 100 & 1,000 & \\
CXCR4 & & & & \\
Alive patients & 1.0 & 19 & 165.1 & $>0.05$ \\
Deceased patients & 5.5 & 26 & 100 & \\
\hline
\end{tabular}

The Mann-Whitney U test was performed for statistical significance (P-value).
miR-494.3p transfection in SS cell lines. To verify the role of CXCR4 as a potential miR-494.3p target, the SW982 and SYO-I cell lines with a minimal expression of miR-494.3p ( $2^{-\mathrm{ACq}}$ values: 0.03 and 0.06 , respectively), were transfected with the miR-494.3p precursor. The transfection efficiency was 80.58 and $81.52 \%$ at 48 and $72 \mathrm{~h}$, respectively for the SW982 cells, and 71.45 and $56.15 \%$ at 48 and $72 \mathrm{~h}$, respectively for the SYO-1 cells (Fig. 3A). RT-PCR analysis confirmed the increased expression of miR-494.3p in the SW982-transfected cells compared to the scramble control (116 and 4,407-fold change at 48 and $72 \mathrm{~h}$, respectively), as well as in the SYO-I-transfected cells (519-fold at $48 \mathrm{~h}$ and 4,092-fold change at 72 h) (Fig. 3B). Accordingly, a decrease in the levels of its potential target gene, CXCR4, was found in the transfected cells compared to the scramble control, reaching statistical significance in the SYO-I at $48 \mathrm{~h}(\mathrm{P}=0.02)$ (Fig. 3C). A decreased protein expression of CXCR4 was also observed by FACS analysis up to $72 \mathrm{~h}$ of transfection (Fig. 4).

Effect of miR-494.3p ectopic expression on SS cell lines. When compared to the scramble control, both the SW982 


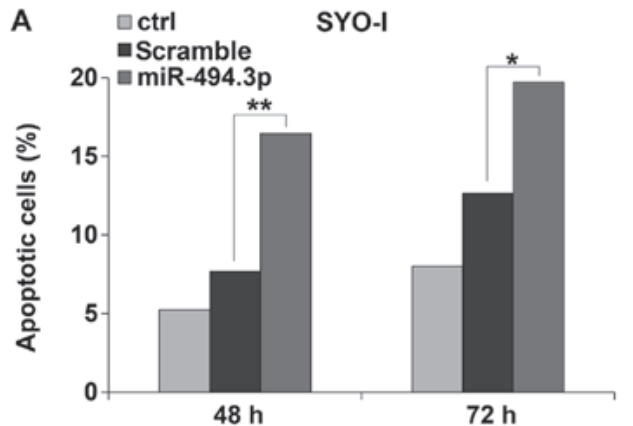

B

SW982

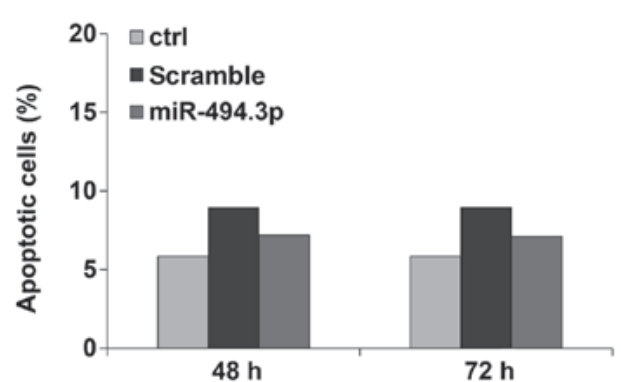

Figure 6. Ectopic miR-494.3p and apoptosis. miRNA transfection led to a significant increase in the apoptosis of (A) SYO-I cells which was more evident at $48 \mathrm{~h}$, while no significant difference was observed in the (B) SW982 cells. Statistically significant differences were determined between miRNA-transfected cells and the scramble control using the t-test. ${ }^{*} \mathrm{P} \leq 0.05$ and ${ }^{* * *} \mathrm{P} \leq 0.01$; ctrl, control, cells under basal condition.

A

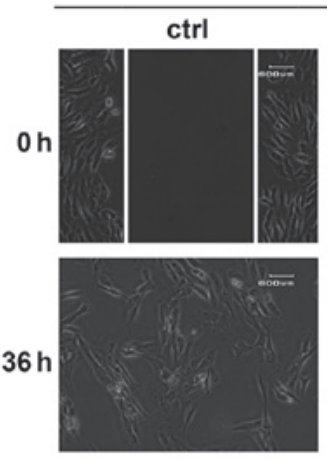

B
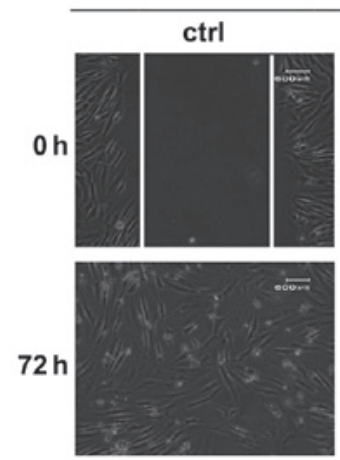

SW982
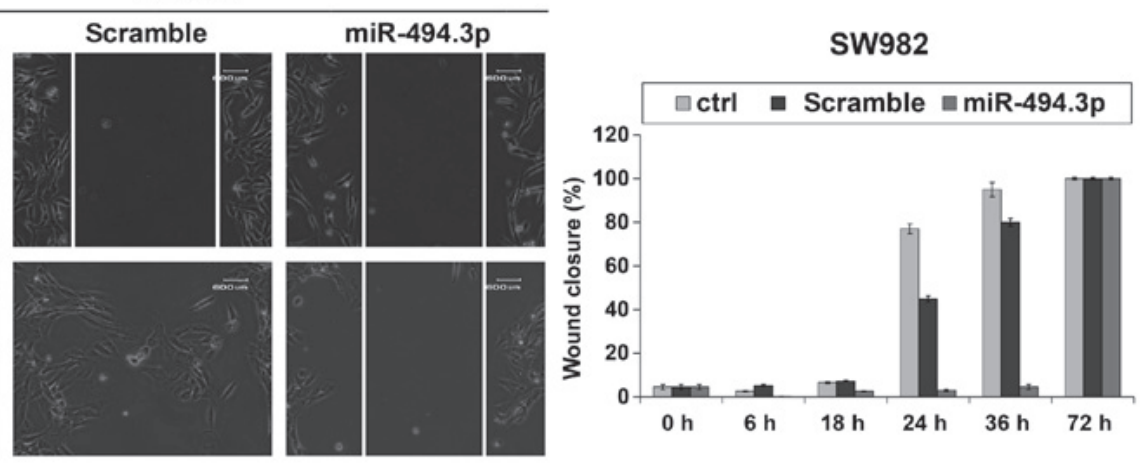

SYO-I

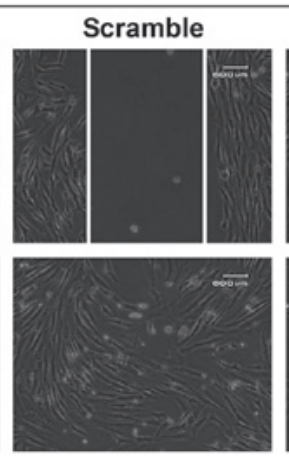

$\operatorname{miR}-494.3 p$

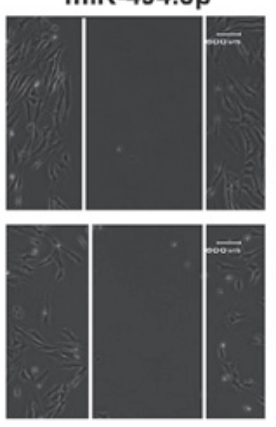

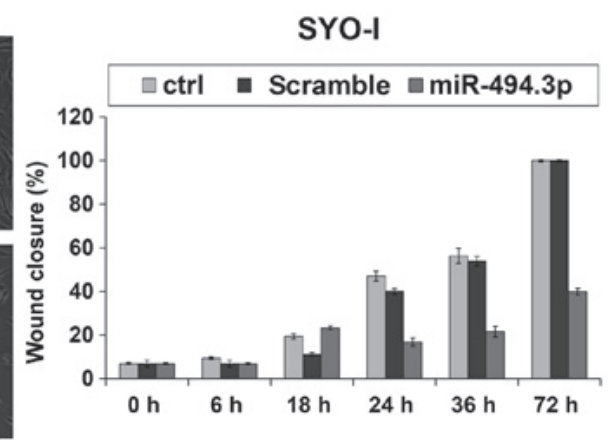

Figure 7. Ectopic miR-494.3p expression and cell migration. miRNA transfection caused a decrease in the migration of both cell lines; in the (A) SW982 up to $36 \mathrm{~h}$, and in the (B) SYO-I cells up to $72 \mathrm{~h}$. The difference between miRNA-transfected cells and the scramble control was examined using a t-test; however, the difference did not reach statistical significance. ctrl, control, cells under basal condition.

and SYO-1 cells responded to miR-494.3p transfection with a significant decrease in cell proliferation, of 86.42 and $77.21 \%$, respectively at $48 \mathrm{~h}(\mathrm{P}=0.001)$ and of $54.22 \%$ and $33.33 \%$, respectively at $72 \mathrm{~h}(\mathrm{P}=0.001)$ (Fig. 5).

Concomitantly, the SYO-I cells responded with a significant increase in the apoptotic fraction: $16.4 \%$ vs. $7.7 \%$ at $48 \mathrm{~h}$ $(\mathrm{P}=0.01)$ and $19.7 \%$ vs. $12.6 \%$ at $72 \mathrm{~h}(\mathrm{P}=0.05)$ (Fig. $6 \mathrm{~A})$. No significant changes were found for the SW982 cells (Fig. 6B).

Migration assay revealed that the ectopic expression of miR-494.3p attenuated the migration of the SW982 cells up to $36 \mathrm{~h}$ shifting to control values at $72 \mathrm{~h}$ (Fig. 7A), while the SYO-I cells also exhibited a slower migration, reaching a complete coverage of the scratch area only after 72 h(Fig. 7B).

\section{Discussion}

SS is an aggressive tumour responsible of 7-8\% of malignant sarcomas. Localized SS has a high overall survival; however, in relapsed patients the 5-year survival rate is $20-30 \%$ with therapeutic strategies limited to surgical resection assisted by radiotherapy, since chemotherapy is often ineffective and lacks specific protocols (21). Following the failure of anthracyclines, the multi-kinase inhibitor, pazopanib, is the first targeted agent to be approved for the treatment of advanced SS (22); however, other biomarkers are required for prognosis and therapy.

On the bases of our previous results that identified CXCR4 nuclear protein as a strong independent adverse prognostic factor for SS patient survival (11), we analysed the CXCR4 mRNA 
levels in a series of monophasic localized and metastatic SS specimens. The significantly higher expression of the CXCR4 gene in the tumour compared to normal tissue, also observed at protein level, validated the role of the chemokine in tumour development $(9,23)$.

Metastatic patients presented higher CXCR4 levels than metastasis-free patients, with a difference at the limit of statistical significance. Although no associations were found with overall survival or other clinical parameters, probably requiring a larger cohort, as in other STS (24), our data confirmed the association between CXCR4 overexpression and poor prognosis in SS.

Biological data suggest that CXCR4 is a possible candidate target of miR-494.3p that is often found downregulated in tumours $(16,17)$. Several studies have demonstrated a deregulation of miRNAs in sarcoma, including SS (25) and Subramanian et al suggested an association between miR-143 and the regulation of the $S Y T / S S X-1$ fusion gene (14). However, to date no evidence of a correlation between miRNA expression and SS translocation fusion genes has been found, at least to the best of our knowledge. In chondrosarcoma, a low expression of miR-494.3p has been shown to be associated with a poor prognosis (18).

In this study, miR-494.3p expression was significantly lower in tumour compared to normal tissue. The opposite trend of miR-494.3p and CXCR4 in SS emphasized the role of miR-494.3p as a post-transcriptional regulator of CXCR4, confirming previous data in prostate and breast cancer cells where this role was observed by CXCR4 inhibition following miR-494.3p mimic transfection $(16,17)$.

In this study, concomitantly with higher CXCR4 levels, patients with SS with metastasis presented with lower miR-494.3p levels when compared to those with no metastasis. In order to demonstrate whether SS cell behaviour was modulated by miR-494.3p through its potential target CXCR4, we transfected SW982 and SYO-I cell lines with miR-494-3p precursor. The significant decrease in CXCR4 expression was associated with a decrease in cell proliferation which was more evident in the SYO-I cells, that also responded with a significant increase in the apoptotic cell fraction in accordance with data on chronic myeloid leukemia and prostate cancer $(16,26)$.

In the SW982 cells we found that the significant decrease in cell proliferation was not accompanied by an increased apoptotic fraction probably due to a different apoptotic pathway compared to the SYO-I cells $(27,28)$. The overexpression of miR-494.3p also inhibited ovarian cancer cell proliferation by inducing apoptosis via FGFR2 (29), while in hepatocellular carcinoma it conferred chemotherapy resistance by targeting PTEN and increasing AKT expression (30).

By the evidence that the CXCL12/CXCR4 pathway may play a role in the development of metastatic disease in STS (9) we assessed the effect of CXCR4 modulation on SS cell migration. Both the SW982 and SYO cells responded to miR-494.3p overexpression by decreasing cell motility, lasting longer in the SYO-I cells. Some data reported the role of miR-494.3p as a promoter of cell migration in breast and lung cancer $(31,32)$, while by targeting different pathways it also inhibited cell proliferation, migration and invasion in ovarian cancer (29), gastric cancer (33), osteosarcoma (19) and chondrosarcoma (18).

In conclusion, the data of this study demonstrated a negative significant correlation between CXCR4 and
miR-494.3p expression in SS surgical specimens and revealed that non-metastatic patients presented a lower expression of CXCR4 concomitant with higher levels of miR-494.3p when compared to metastatic patients. In vitro studies confirmed that miR-494.3p transfection caused a reduction in its potential target CXCR4, concomitant with a decrease in cell migration and proliferation. Ongoing studies are required to better clarify the clinical impact of CXCR4 in terms of prognostic and therapeutic biomarker in SS.

\section{Acknowledgements}

The authors wish to thank Dr A. Kawai for kindly providing the SYO-I cell line, Dr Alba Balladelli for editing the manuscript and Ms. Cristina Ghinelli for graphic work.

\section{Funding}

This study was supported by $5 \%$ o citizen income tax contribution to the Rizzoli Orthopaedic Institute and Italian Health Ministry.

\section{Availability of data and materials}

All data generated or analyzed during this study are included in this published article.

\section{Authors' contributions}

LP performed the experiments, analysed data and wrote the manuscript; SP performed the experiments and analysed the data; MV and EB performed the experiments; SB and MG were in charge of the pathological specimens; CF and EP were involved in patient follow-up; PP conceived the study and approved the final version to be published; MSB conceived the study, performed statistical analysis, wrote the manuscript, and approved the final version to be published. All authors have read and approved the contents of this manuscript and declare that the work is original and had not been submitted or published elsewhere.

\section{Ethics approval and consent to participate}

All samples were treated in accordance with the authorizations issued by the Ethics Committee of the the Rizzoli Orthopedic Institute (no. 0033276) and written informed consent was obtained from all patients.

\section{Patient consent for publication}

Not applicable.

\section{Competing interests}

The authors declare that they have no competing interests.

\section{References}

1. Picci P, Manfrini M, Fabbri N, Gambarotti M and Vanel D (eds.): Synovial sarcoma. In: Atlas of Musculoskeletal Tumors and Tumor like Lesions. Springer International Publishing, Cham, pp359-364, 2014. 
2. Quail DF and Joyce JA: Microenvironmental regulation of tumor progression and metastasis. Nat Med 19: 1423-1437, 2013.

3. Furusato B, Mohamed A, Uhlén M and Rhim JS: CXCR4 and cancer. Pathol Int 60: 497-505, 2010.

4. Kim J, Mori T, Chen SL, Amersi FF, Martinez SR, Kuo C, Turner RR, Ye X, Bilchik AJ, Morton DL, et al: Chemokine receptor CXCR4 expression in patients with melanoma and colorectal cancer liver metastases and the association with disease outcome. Ann Surg 244: 113-120, 2006.

5. Müller A, Homey B, Soto H, Ge N, Catron D, Buchanan ME, McClanahan T, Murphy E, Yuan W, Wagner SN, et al: Involvement of chemokine receptors in breast cancer metastasis. Nature 410: 50-56, 2001.

6. Koshiba T, Hosotani R, Miyamoto Y, Ida J, Tsuji S, Nakajima S, Kawaguchi M, Kobayashi H, Doi R, Hori T, et al: Expression of stromal cell-derived factor 1 and CXCR4 ligand receptor system in pancreatic cancer: A possible role for tumor progression. Clin Cancer Res 6: 3530-3535, 2000.

7. Schimanski CC, Schwald S, Simiantonaki N, Jayasinghe C, Gönner U, Wilsberg V, Junginger T, Berger MR, Galle PR and Moehler M: Effect of chemokine receptors CXCR4 and CCR7 on the metastatic behavior of human colorectal cancer. Clin Cancer Res 11: 1743-1750, 2005.

8. Zeelenberg IS, Ruuls-Van Stalle L and Roos E: The chemokine receptor CXCR4 is required for outgrowth of colon carcinoma micrometastases. Cancer Res 63: 3833-3839, 2003.

9. Kim RH, Li BD and Chu QD: The role of chemokine receptor CXCR4 in the biologic behavior of human soft tissue sarcoma. Sarcoma 2011: 593708, 2011.

10. Li YJ, Dai YL, Zhang WB, Li SJ and Tu CQ: Clinicopathological and prognostic significance of chemokine receptor CXCR4 in patients with bone and soft tissue sarcoma: A meta-analysis. Clin Exp Med 17: 59-69, 2017

11. Palmerini E, Benassi MS, Quattrini I, Pazzaglia L, Donati D, Benini S, Gamberi G, Gambarotti M, Picci P and Ferrari S: Prognostic and predictive role of CXCR4, IGF-1R and Ezrin expression in localized synovial sarcoma: is chemotaxis important to tumor response? Orphanet J Rare Dis 10: 6, 2015.

12. Bartel DP: MicroRNAs: Genomics, biogenesis, mechanism, and function. Cell 116: 281-297, 2004.

13. Kloosterman WP and Plasterk RH: The diverse functions of microRNAs in animal development and disease. Dev Cell 11: 441-450, 2006

14. Subramanian S, Lui WO, Lee $\mathrm{CH}$, Espinosa I, Nielsen TO, Heinrich MC, Corless CL, Fire AZ and van de Rijn M: MicroRNA expression signature of human sarcomas. Oncogene 27: 2015-2026, 2008.

15. Fujiwara T, Kunisada T, Takeda K and Ozaki T: MicroRNAs and soft tissue sarcomas. Adv Exp Med Biol 889: 179-199, 2015.

16. Shen PF, Chen XQ, Liao YC, Chen N, Zhou Q, Wei Q, Li X, Wang J and Zeng H: MicroRNA-494-3p targets CXCR4 to suppress the proliferation, invasion, and migration of prostate cancer. Prostate 74: 756-767, 2014

17. Song L, Liu D, Wang B, He J, Zhang S, Dai Z, Ma X and Wang X: miR-494 suppresses the progression of breast cancer in vitro by targeting CXCR4 through the Wnt/ $\beta$-catenin signaling pathway. Oncol Rep 34: 525-531, 2015.

18. Li J, Wang L, Liu Z, Zu C, Xing F, Yang P, Yang Y, Dang X and Wang K: MicroRNA-494 inhibits cell proliferation and invasion of chondrosarcoma cells in vivo and in vitro by directly targeting SOX9. Oncotarget 6: 26216-26229, 2015.

19. Zhi X, Wu K, Yu D, Wang Y, Yu Y, Yan P and Lv G: MicroRNA-494 inhibits proliferation and metastasis of osteosarcoma through repressing insulin receptor substrate-1. Am J Transl Res 8: 3439-3447, 2016
20. Livak KJ and Schmittgen TD: Analysis of relative gene expression data using real-time quantitative PCR and the $2(-\Delta \Delta \mathrm{C}(\mathrm{T}))$ Method. Methods 25: 402-408, 2001.

21. Krieg AH, Hefti F, Speth BM, Jundt G, Guillou L, Exner UG, von Hochstetter AR, Cserhati MD, Fuchs B, Mouhsine E, et al: Synovial sarcomas usually metastasize after $>5$ years: A multicenter retrospective analysis with minimum follow-up of 10 years for survivors. Ann Oncol 22: 458-467, 2011.

22. van der Graaf WT, Blay JY, Chawla SP, Kim DW, Bui-Nguyen B, Casali PG, Schöffski P, Aglietta M, Staddon AP, Beppu Y, et al; EORTC Soft Tissue and Bone Sarcoma Group; PALETTE study group: Pazopanib for metastatic soft-tissue sarcoma (PALETTE): A randomised, double-blind, placebo-controlled phase 3 trial. Lancet 379: 1879-1886, 2012.

23. Balkwill F: The significance of cancer cell expression of the chemokine receptor CXCR4. Semin Cancer Biol 14: 171-179, 2004.

24. Oda Y, Tateishi N, Matono H, Matsuura S, Yamamaoto H, Tamiya S, Yokoyama R, Matsuda S, Iwamoto Y and Tsuneyoshi M: Chemokine receptor CXCR4 expression is correlated with VEGF expression and poor survival in soft-tissue sarcoma. Int J Cancer 124: 1852-1859, 2009.

25. Yu PY,Balkhi MY,Ladner KJ, Alder H, Yu L,Mo X, Kraybill WG, Guttridge DC and Iwenofu $\mathrm{OH}$ : A selective screening platform reveals unique global expression patterns of microRNAs in a cohort of human soft-tissue sarcomas. Lab Invest 96: 481-491, 2016.

26. Salati S, Salvestrini V, Carretta C, Genovese E, Rontauroli S, Zini R, Rossi C, Ruberti S, Bianchi E, Barbieri G, et al: Deregulated expression of miR-29a-3p, miR-494-3p and miR-660-5p affects sensitivity to tyrosine kinase inhibitors in CML leukemic stem cells. Oncotarget 8: 49451-49469, 2017.

27. Jones KB, Su L, Jin H, Lenz C, Randall RL, Underhill TM, Nielsen TO, Sharma S and Capecchi MR: SS18-SSX2 and the mitochondrial apoptosis pathway in mouse and human synovial sarcomas. Oncogene 32: 2365-2371, 2013.

28. Joyner DE, Albritton KH, Bastar JD and Randall RL: G3139 antisense oligonucleotide directed against antiapoptotic Bcl-2 enhances doxorubicin cytotoxicity in the FU-SY-1 synovial sarcoma cell line. J Orthop Res 24: 474-480, 2006.

29. Zhao X, Zhou Y, Chen YU and Yu F: miR-494 inhibits ovarian cancer cell proliferation and promotes apoptosis by targeting FGFR2. Oncol Lett 11: 4245-4251, 2016.

30. Liu K, Liu S, Zhang W, Jia B, Tan L, Jin Z and Liu Y: miR-494 promotes cell proliferation, migration and invasion, and increased sorafenib resistance in hepatocellular carcinoma by targeting PTEN. Oncol Rep 34: 1003-1010, 2015.

31. Macedo T, Silva-Oliveira RJ,Silva VAO, Vidal DO, Evangelista AF and Marques MMC: Overexpression of mir-183 and mir-494 promotes proliferation and migration in human breast cancer cell lines. Oncol Lett 14: 1054-1060, 2017.

32. Faversani A, Amatori S, Augello C, Colombo F, Porretti L, Fanelli M, Ferrero S, Palleschi A, Pelicci PG, Belloni E, et al: miR-494-3p is a novel tumor driver of lung carcinogenesis. Oncotarget 8: 7231-7247, 2017.

33. Zhao XQ, Liang TJ and Fu JW: miR-494 inhibits invasion and proliferation of gastric cancer by targeting IGF-1R. Eur Rev Med Pharmacol Sci 20: 3818-3824, 2016. 